\title{
Involvement of Atm and Trp53 in neural cell loss due to Terf2 inactivation during mouse brain development
}

\author{
Jusik Kim $^{1,2} \cdot$ Inseo Choi $^{1,2} \cdot$ Youngsoo Lee $^{1,2}$ D
}

Accepted: 8 June 2017 / Published online: 15 June 2017

(C) The Author(s) 2017. This article is an open access publication

\begin{abstract}
Maintenance of genomic integrity is one of the critical features for proper neurodevelopment and inhibition of neurological diseases. The signals from both ATM and ATR to TP53 are well-known mechanisms to remove neural cells with DNA damage during neurogenesis. Here we examined the involvement of Atm and Atr in genomic instability due to Terf2 inactivation during mouse brain development. Selective inactivation of Terf 2 in neural progenitors induced apoptosis, resulting in a complete loss of the brain structure. This neural loss was rescued partially in both Atm and Trp53 deficiency, but not in an Atr-deficient background in the mouse. Atm inactivation resulted in incomplete brain structures, whereas $p 53$ deficiency led to the formation of multinucleated giant neural cells and the disruption of the brain structure. These giant neural cells disappeared in Lig4 deficiency. These data demonstrate ATM and TP53 are important for the maintenance of telomere homeostasis and the surveillance of telomere dysfunction during neurogenesis.
\end{abstract}

Keywords Atm · DNA damage $\cdot$ Apoptosis $\cdot$ Brain development

Electronic supplementary material The online version of this article (doi:10.1007/s00418-017-1591-3) contains supplementary material, which is available to authorized users.

Youngsoo Lee

ysoolee@ajou.ac.kr

1 Genomic Instability Research Center, School of Medicine, Ajou University, Suwon 16499, Republic of Korea

2 Department of Biomedical Sciences, The Graduate School, Ajou University, Suwon 16499, Republic of Korea

\author{
Abbreviations \\ DSBs DNA double-strand breaks \\ DDR DNA damage response \\ P Postnatal day \\ E Embryonic day \\ VZ Ventricular zone \\ CC Corpus callosum
}

\section{Introduction}

Genomic instability resulting from DNA damage induced by either endogenous or exogenous insults could lead to defective neurodevelopment and neurological diseases (Lee et al. 2016). Ataxia telangiectasia mutated (ATM) is one of the early responders to DNA damage, particularly to DNA double-strand breaks (DSBs). ATM mutations cause Ataxia Telangiectasia (A-T) characterized by ataxia due to loss of Purkinje and granule cells in the cerebellum (McKinnon 2012, 2013). Similarly, Ataxia-telangiectasia and RAD3related (ATR) recognizes single-stranded DNA resulting from replication stress. Seckel syndrome 1 (SCKL1) due to hypomorphic mutations in the ATR gene is characterized by microcephaly and mental retardation (Nam and Cortez 2011; McKinnon 2013). Once activated by DNA damage, ATM and ATR phosphorylate several overlapping substrates including tumor protein p53 (TP53/Trp53 in mice) to regulate DNA damage repair, apoptosis, and cell cycle arrest (Lee et al. 2001, 2012b; Lovejoy and Cortez 2009). Although it is well known that ATM and ATR are required to maintain genomic integrity, the precise roles of ATM and ATR during brain development are not fully understood, especially related to neuropathology such as ataxia, neurodegeneration, and microcephaly observed in human patients. 
Telomere dysfunction is one of the endogenous sources to induce DNA damage response (DDR), since the unprotected telomere ends could be recognized as DNA strand breaks (de Lange 2005). To protect this DNA region, the telomere ends are coated with the Shelterin complex, which is composed of several proteins including telomeric repeat binding factor 2 (TERF2) and protection of telomeres 1 (POT1), to prevent telomere attrition and inappropriate DDR induction (de Lange 2005; Palm and de Lange 2008). TERF2 homodimers bind to double-stranded regions of telomeres and inactivation of TERF2 triggers ATM-dependent DDR signals, whereas POT1 protects the $3^{\prime}$ single-stranded overhang and its inactivation initiates ATR-dependent DDR signals at the cellular level (Karlseder et al. 1999; Zhang et al. 2006, 2007; Denchi and de Lange 2007; Sfeir and de Lange 2012). The exposed telomere ends as a result of Terf2 inactivation were processed by DNA ligase IV (Lig4) which is the ligase for the canonical Non-homologous endjoining repair (NHEJ) pathway for DSBs (Celli and de Lange 2005; Lee et al. 2016; Smogorzewska et al. 2002). The involvement of ATM and ATR in DDR induced by telomere dysfunction was mutually exclusive in this context.

However, selective deletion of the Potla gene during mouse brain development resulted in Atm-dependent neurological phenotypes including cerebellar defects, suggesting that telomere dysfunction might induce DDR in a tissue-specific manner during neurogenesis (Lee et al. 2014). For the current study, we asked whether telomere dysfunction due to Terf2 inactivation also induces neuro-specific DDR associated with Atm or Atr signaling pathway during neurogenesis.

\section{Materials and methods}

\section{Animals}

Floxed Terf2 animals (Karlseder et al. 1999; Celli and de Lange 2005) were purchased from the Jackson Laboratory (JAX \#006568). Germline deletion of the Terf2 gene caused embryonic lethality at mid-gestation in the mouse (Celli and de Lange 2005). In order to restrict inactivation of the Terf 2 gene in the nervous system during development, Terf $2^{L o x P /+}$ animals were interbred with Nestin-Cre animals (JAX \#003771) or Emxl-Cre animals (JAX \#005628). Cre recombinase expression driven by the Nestin promoter is active around embryonic day (E) 11 throughout the neural progenitors, whereas the Emxl promoter is activated only in the dorsal telencephalon and the hippocampal progenitors around E10 during mouse embryogenesis (Gorski et al. 2002; Graus-Porta et al. 2001; Tronche et al. 1999). Terf2 $2^{\text {LoxP/LoxP }} ;$ Nestin-Cre and $\operatorname{Terf} 2^{\text {LoxP/LoxP }} ;$ Emxl-Cre mice were obtained through a proper breeding scheme. Conditional knockout animals could not be used for breeding. Terf $2^{\text {LoxP/+ }}$;Nestin-Cre or Emxl-Cre animals did not show any discernable defects or shortened life span, and they were fertile. So these animals were included in control groups. Mutant alleles of Atm, Atr ${ }^{\text {LoxP }}, \operatorname{Trp}^{2} 3^{\text {LoxP }}, \mathrm{Lig}^{\mathrm{LoxP}}$, and Pot $1 a^{\text {LoxP }}$ genes and the polymerase chain reaction (PCR) conditions for genotyping were as previously described (Lee et al. 2001, 2012b, 2014; Shull et al. 2009). All animals were maintained in a mixed strain of C57BL/6 X 129 genetic background. Since we could not find any gender difference of DDR in the brain before (Lee et al. 2001, 2012a, 2014), we analyzed the experimental materials regardless of gender for the current study. Also Nestin-Cre expression was maintained in females for breeding to minimize any ectopic Cre recombinase activity outside of the nervous system. Genotypes of genetically engineered animals were determined by a routine PCR method using the following primers: Terf2 (Forward: 5' ccaaccagggatacacagtga, Reverse: $5^{\prime}$ atccgtagttcctcttgtgtctg), Pot la (Forward: $5^{\prime}$ ctcgaattccatctcctcccagtactctctcag, Reverse: 5 ggaactggtacgtatcagtgtgtgtgg), Atm wildtype ( WT) allele (Forward: $5^{\prime}$ gcctgtatcttctatgtgcaccgtcttcgc, Reverse: $5^{\prime}$ ggtgcggtgtggatgggactggagg), Atm targeted allele (Forward: $5^{\prime}$ gtgatgacctgagacaagatgctgtc, Reverse: $5^{\prime}$ gggaagacaatagcaggcatgc), Atr (Forward: 5 tacattttagtcatagttgcataacac, Reverse: 5 cttctaatcttcctccagaattgtaaaagg), Lig4 (Forward: $5^{\prime}$ atcgctcttgtcccagtacacctgc, Reverse: 5 gtgcattaaatggagtgctgtgc), Trp53 (Forward: 5' cacaaaaacaggttaaacccag, Reverse: $5^{\prime}$ agcacataggaggcagagac).

PCR products for Terf2 genotyping were amplified for 35 cycles of $94{ }^{\circ} \mathrm{C}$ for $30 \mathrm{~s}, 60{ }^{\circ} \mathrm{C}$ for $45 \mathrm{~s}$, and $72{ }^{\circ} \mathrm{C}$ for $45 \mathrm{~s}$. PCR products for WT and floxed alleles $(\operatorname{Lox} P)$ of the Terf 2 gene were 233 and $300 \mathrm{bp}$, respectively.

All of animal materials for experiments were courteously provided by Dr. Peter McKinnon (St. Jude Children's Research Hospital, USA). The presence of a vaginal plug was indicated as E.5 and the day of birth as postnatal day (P) 0. All animals were housed in an AAALAC accredited facility and were maintained in accordance with the National Institutes of Health "Guide for the Care and Use of Laboratory Animals'. All procedures for animal use were approved by the Institutional Animal Care and Use Committee.

\section{Histology}

Histopathological procedures were performed as previously described (Lee et al. 2012a, 2014). In brief, both embryos and brains were collected at indicated time points after the fixation step using $4 \%$ phosphate-buffered paraformaldehyde. Cryosections of embryos or brains at $10 \mu \mathrm{m}$ were collected using an HM500M (Microm) or an MEV (SLEE 


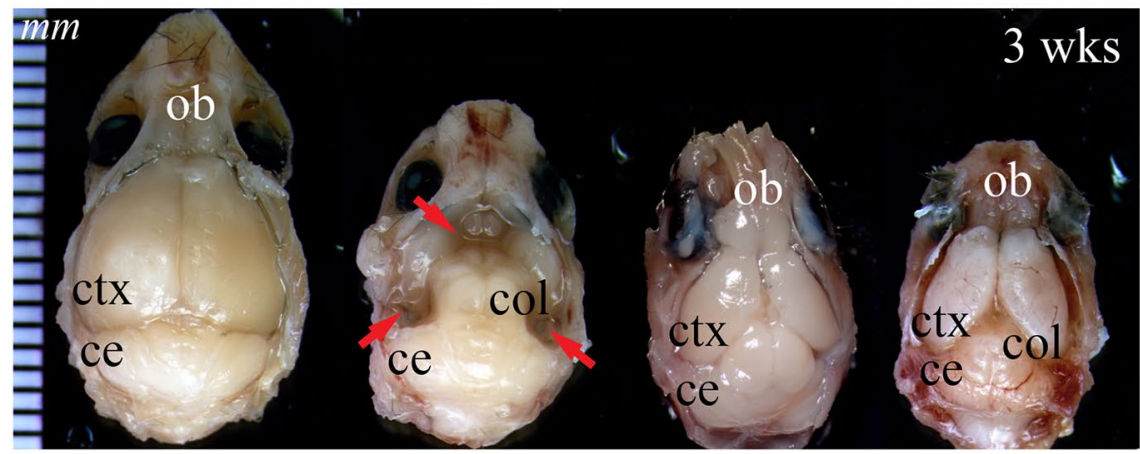

$$
\operatorname{Terf2}{ }^{\text {ctrl }} \operatorname{Terf2} 2^{\text {Emxl-Cre }} \frac{\mathrm{Atm}^{-/} \operatorname{Trp}^{2} 3^{\text {Emxl-Cre }}}{\operatorname{Terf} 2^{\text {Emxl-Cre }}}
$$

b

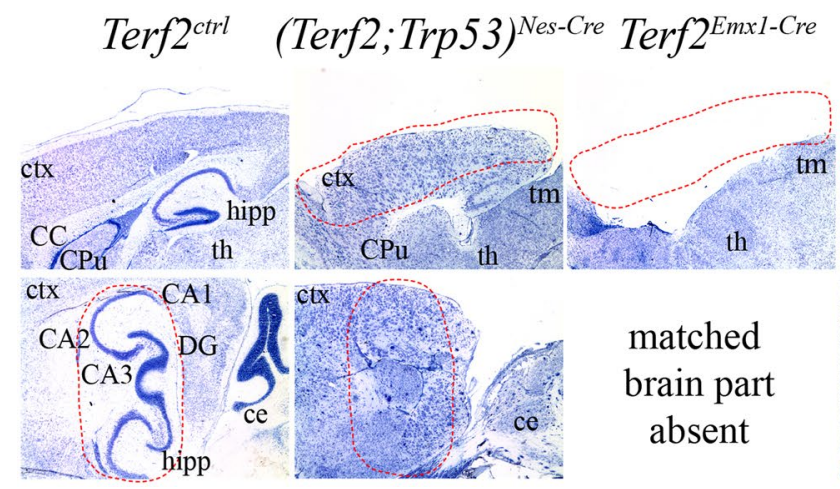

Fig. 1 Terf2 inactivation during neurogenesis resulted in obliteration of the brain structure. a The view from the top of Terf 2 conditional knockout brains at 3 weeks of age. The skull was partially removed to show the brain structure. The eyeballs were intact. The control brain was fully developed, yet the Terf $2^{\text {Emxl-Cre }}$ brain had the cerebral cortical part missing in which the Emx1 promoter-driven Cre recombinase was expressed, so the colliculus (col) was fully exposed. Red arrows indicate the part lost in the Terf $2^{\text {Emxl-Cre }}$ brain. These missing brain parts were partially restored in both Atm and Trp53-null backgrounds. $c e$ cerebellum, col colliculus, $c t x$ cerebral cortex, $o b$ olfactory bulb. Ctrl control, the ruler in $\mathrm{mm}$. b Nissl staining of the mature brains. The sagittal (upper panel) and parasagittal (lower panel) views of 3 -week-old brains in different genetic backgrounds. Upper panel the brain areas expressing Cre recombinase controlled by the Emxl promotor were completely missing (Terf $\left.2^{\text {Emxl-Cre }}\right)$, but the partial recovery of the brain areas was observed in Atm-, Trp53- and Lig4/ Trp53-null backgrounds (Terf2 ${ }^{\text {Emxl-Cre }} ; \mathrm{Atm}^{-1-},\left(\right.$ Terf2;Trp53) ${ }^{\text {Emxl-Cre }}$

medical $\mathrm{GmbH}$ ) cryostat for pathological analysis. Hematoxylin and Eosin (H/E), and Nissl staining were carried out in a routine procedure. Immunoreactivity was visualized by either colorimetric detection using the VIP substrate kit (Vector Labs) reactive with biotinylated secondary antibodies or fluorometric detection using FITC/CY3 conjugated secondary antibodies (Jackson Immunologicals) after incubation with primary antibodies. Counterstaining was done and $($ Terf2;Lig4;Trp53) Emxl-Cre $)$. Also Trp53 deficiency rescued embryonic lethality as well as partially the missing brain structure in Terf $2^{\text {Nes-Cre }}$ animals. Lower panel the hippocampus, one of the important brain structures for memory, in the conditional knockout brains was not formed. Either Atm or Trp53 deficiency was not sufficient enough to restore the hippocampal structure. However, the (Terf2;Lig4;Trp53) Emxl-Cre brain displayed a partial recovery of the hippocampus. In the parasagittal section, the matched brain part containing the hippocampus in the Emx-1 Cre background was completely gone, since the Emxl-Cre was expressed in this particular brain structure during neurogenesis. The dotted red lines demarcate some brain areas affected by Terf 2 inactivation, such as the cerebral cortex and hippocampus. $C C$ corpus callosum, ce cerebellum, $C p u$ caudate putamen, $c t x$ cerebral cortex, th thalamus, hipp hippocampus (CA1/2/3 Cornu Ammonis areas 1/2/3, DG dentate gyrus), tm tectum. The scale bar is $1.2 \mathrm{~mm}$

with $0.1 \%$ methyl green in $0.1 \mathrm{M}$ sodium acetate buffer for colorimetric staining followed by mounting with DPX (Sigma) or DAPI/PI counterstaining mounting medium (Vector Laboratories) for fluorometric staining.

Antibodies used for this study were Calbindin (mouse, 1:2000, Sigma-Aldrich), Ctip2 (rat, 1:100, Abcam), Cux1 (rabbit, 1:100, Santa Cruz), Foxp2 (rabbit, 1:500, Abcam), GFAP (mouse, 1:500, Sigma-Aldrich), $\gamma$-H2AX (rabbit, 

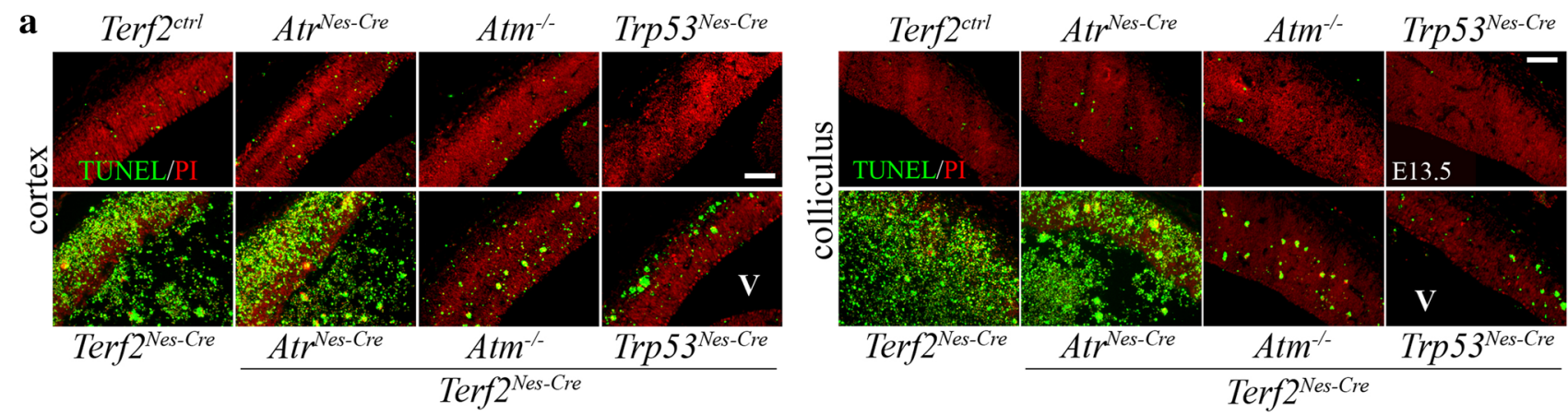

$\mathbf{b}$
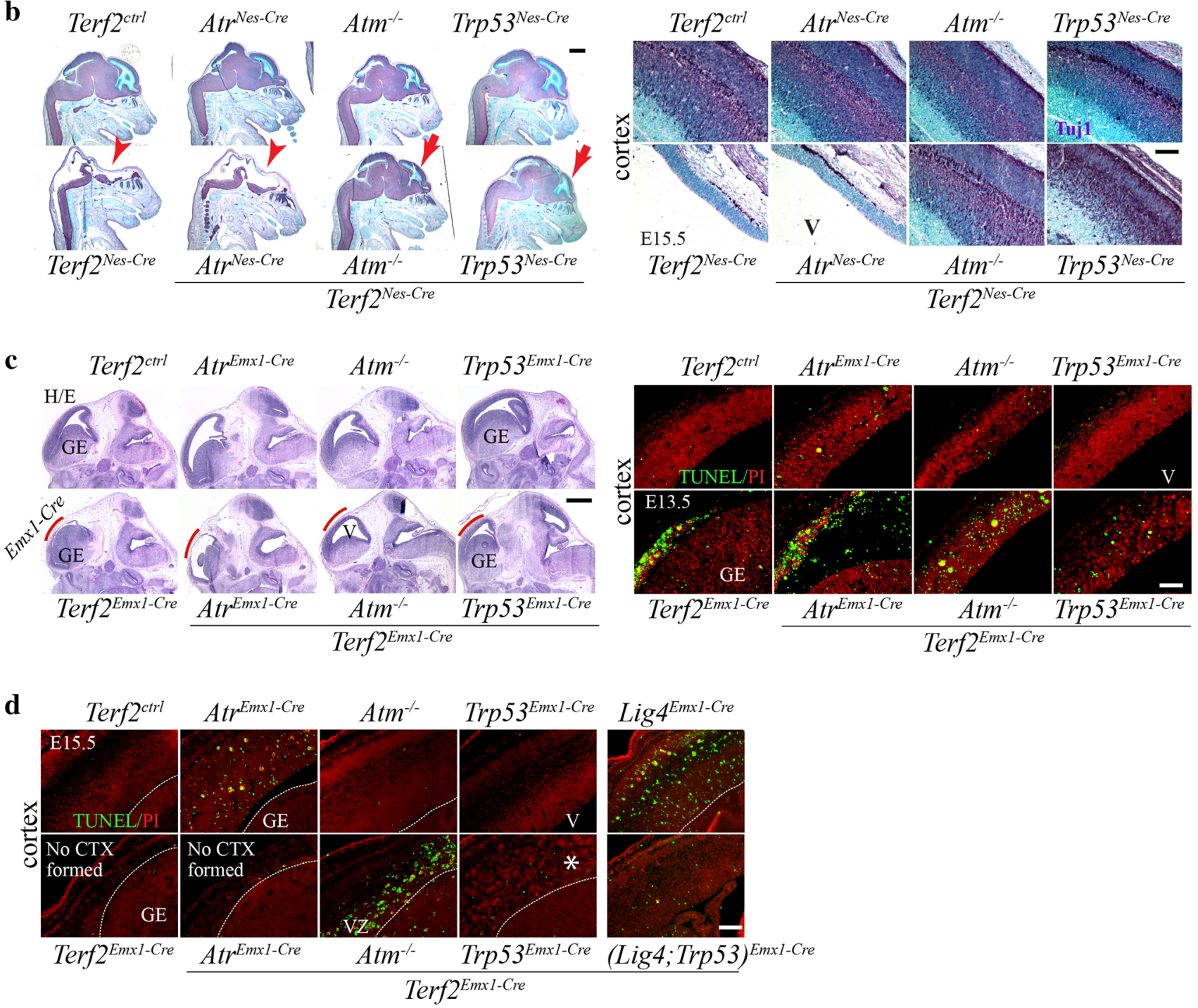

1:100, Cell signaling), $\gamma$-tubulin (mouse, 1:1000, SigmaAldrich), Histone H3phosphoS10 (rabbit, 1:2000, Cell signaling), MBP (myelin basic protein, rabbit, 1:200, Abcam), Myelin-PLP (rabbit, 1:200, Abcam), NeuN (mouse, 1:500, Millipore), Neuronal Class III $\beta$ tubulin (clone TUJ1, mouse, 1:1000, Covance Research), Tbr1 (rabbit, 1:500, Abcam). Depending on primary antibodies, the citric acid-based antigen retrieval method was applied to enhance immunoreactive signals.

TUNEL (terminal deoxynucleotidyl transferase dUTP nick end labeling) assay using Apoptag (Chemicon) was applied to measure apoptosis. Multiple histological slides were examined and imaged using an Axio Imager A1 microscope (Zeiss) or B600TiFL (Optika). Microscopic 
4Fig. 2 Massive apoptosis occurred in the Terf2-deficient developing brain. a TUNEL analysis to detect neural apoptosis. The embryonic forebrain (cortex) and colliculus area at embryonic day (E) 13.5 with TUNEL staining. The controls $\left(\mathrm{Terf}^{2 \mathrm{ctrl}}, \mathrm{Atr}^{\mathrm{Nes}-\mathrm{Cre}}, \mathrm{Atm}^{-/-}\right.$ and Trp $53^{\text {Nes-Cre }}$ ) showed only the basal levels of TUNEL positivity (green staining), and there was no difference among the control groups. However, massive apoptosis was observed in the Terf $2^{\text {Nes-Cre }}$ and $(\text { Terf } 2 \text {;Atr })^{\text {Nes-Cre }}$ developing brains, while a dramatic reduction of programmed cell death was evident in both $\mathrm{Terf} 2^{\mathrm{Nes}-\mathrm{Cre}} ; \mathrm{Atm}^{-1-}$ and $(\text { Terf2;Trp53) })^{\text {Nes-Cre }}$ embryonic cortex and colliculus. Green fluorescent apoptotic debris were falling off inside of the ventricle $(V)$ in

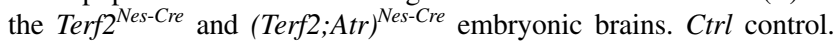
b Tuj1 (Neuron-specific class III beta-tubulin, marker for postmitotic neurons) positive immuno-staining. Left panel the heads of embryos (at E15.5) with Tuj1 immunoreactivity (purple color) at low magnification show that the Terf $2^{\text {Nes-Cre }}$ and $(\text { Terf } 2 ; \text { Atr })^{\text {Nes-Cre }}$ brains were completely gone by E15.5 (red arrowheads), yet the brain structure was partially rescued in both Atm and Trp53 deficiency (red arrows). The ventricular zone was not positive for Tuj1 immunoreactivity, so methyl green staining (counterstaining) was visible in this zone. Right panel high magnified views of the forebrains (cortex) in experimental groups. The Terf $2^{\text {Nes-Cre }}$ and (Terf2;Atr) $)^{\text {Nes-Cre }}$ embryos did not have any brain structure which was positive for Tuj1 immuostaining (purple color). Two pictures of Terf $2^{\text {Nes-Cre }}$ and (Terf2;Atr) $)^{\text {Nes-Cre heads }}$ show only a part of the skull and scalp. The missing brain parts were restored in both Atm and Trp53 null backgrounds (Terf2 ${ }^{\mathrm{Nes}-\mathrm{Cre}} ; \mathrm{Atm}^{-1-}$ and $\left.(\operatorname{Terf} 2 ; \operatorname{Tr} 553)^{\text {Nes-Cre }}\right)$. Methyl green was used for counterstaining so that the ventricular zone could be identifiable. $V$ ventricle. c H/E and TUNEL staining of the Emxl-Cre expressing brains at E13.5. Left panel Hematoxylin/Eosin (H/E) staining of the embryonic brains shows that the Cre expressing area (red line) was gone in Terf ${ }^{\text {Emxl-Cre }}$

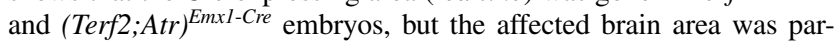
tially restored in both $\mathrm{Atm}^{-1-}$ and Trp $53^{\text {Emxl-Cre }}$ backgrounds. The control animals including Terf $2^{\text {ctrl }}$, Atr ${ }^{\text {Emxl-Cre }}, \mathrm{Atm}^{-1-}$ and Trp $53^{\mathrm{Em} x \mathrm{I}-\mathrm{Cre}}$ brains did not show any morphological defects. The ganglionic

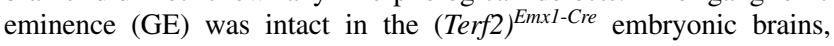
since Emxl-Cre is not expressed in the GE. The red lines demarcate the Emxl-Cre expressing area. $G E$ ganglionic eminence, $V$ ventricle. Right panel apoptosis detected by TUNEL (green color) shows increased apoptosis in the Emxl-Cre expressing area of the Terf2 conditional knockout brains (Terf $2^{\text {Emxl-Cre }}$ and $\left(\right.$ Terf2;Atr) ${ }^{\text {Emxl-Cre }}$ ), but not in the GE. Atm and Trp53 deficiency (but not Atr deficiency) attenuated apoptosis resulting from Terf 2 inactivation in the developing brain. d Apoptosis measured by TUNEL at E15.5. Terf2inactivated brain parts were gone completely in the Terf $2^{\text {Emxl-Cre }}$ and (Terf2;Atr) ${ }^{\text {EmxI-Cre }}$ embryos by E15.5 (No CTX formed). Even though the missing part in the developing brain was partially restored, the Terf $2^{\text {EmxI-Cre }} ; \mathrm{Atm}^{-/-}$forebrain (cortex: CTX) showed apoptosis restricted to the ventricular zone (VZ), and there was no significant sign of programmed cell death observed in the (Terf2;Trp53) ${ }^{\text {Emxl-Cre }}$ and (Terf2;Lig4;Trp53) Emxl-Cre developing brains. However, the restored brain area in a Trp53-null background contained irregular cellularity (white asterisk), which was not observed in the Terf $2^{\text {Emxl-Cre }}$; Atm $^{-1-}$ and (Terf2;Lig4;Trp53) EmxI-Cre embryonic brains. Since Atr or Lig4 inactivation during brain development also induces neuronal cell death, the level of programmed cell death found in the Atr ${ }^{\text {Emxl-Cre }}$

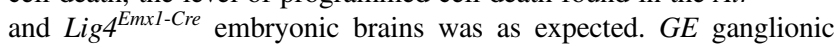
eminence, $V Z$ ventricular zone. The scale bars in $\mathbf{b}$ and $\mathbf{c}$ left panels are $1.2 \mathrm{~mm}$, and the scale bars in the rest of the photomicrographs are $200 \mu \mathrm{m}$ images were captured and processed using Photoshop (v.CS6.5, Adobe).

\section{Telomere in situ using telomere-PNA probe}

To detect telomere in situ, tissue sections were dehydrated in alcohol series, denatured at $80{ }^{\circ} \mathrm{C}$ for $4 \mathrm{~min}$, followed by incubation for $4 \mathrm{~h}$ in the dark at room temperature with CY3-CCCTAACCCTAACCCTAA peptide nucleic acid (PNA) telomere probe $(0.7 \mu \mathrm{g} / \mathrm{ml}$, Panagene) in $70 \%$ formamide, $10 \mathrm{mM}$ Tris- $\mathrm{HCl} \mathrm{pH} 7.5,5 \% \mathrm{MgCl}_{2}$ buffer (82 $\mathrm{mM} \mathrm{Na}_{2} \mathrm{HPO}_{4}, 9 \mathrm{mM}$ citric acid, $25 \mathrm{mM} \mathrm{MgCl}_{2}$ ), and $1 \%$ blocking reagent (Roche). Then, sections were washed with Solution I (70\% formamide, $10 \mathrm{mM}$ Tris- $\mathrm{HCl} \mathrm{pH}$ 7.2, $0.1 \% \mathrm{BSA})$ and Solution II (0.05 M Tris- $\mathrm{HCl} \mathrm{pH} 7.2$, $0.15 \mathrm{M} \mathrm{NaCl}, 0.05 \%$ Tween 20 ) several times. After washing, slides were mounted with DAPI-containing aqueous mounting medium (Vector). Images were captured and analyzed as described in the "Histology" method section.

\section{Results}

\section{Terf 2 was essential for brain development}

It has been reported that germline deletion of the Terf 2 gene caused embryonic lethality at mid-gestation in the mouse (Celli and de Lange 2005). So, we restricted Terf2 inactivation to the nervous system by cross-breeding of the Terf2 floxed animal model with either Nestin-Cre $\left(\right.$ Terf $2^{\text {LoxP/LoxP }} ;$ Nestin-Cre, hereafter Terf $\left.2^{\text {Nes-Cre }}\right)$ or Emx1Cre (Terf $2^{\text {LoxP/LoxP }} ;$ Emxl-Cre, hereafter Terf ${ }^{\text {Emxl-Cre }}$ ) animal lines during development.

Although the Terf 2 gene was targeted only in the nervous system during mouse development, all of Terf $2^{\text {Nes- }}$ Cre mice were born dead without a proper brain structure (data not shown). The overall body size of Terf $2^{\text {Nes-Cre }}$ animals was comparable to that of controls at birth (data not shown). On the other hand, Terf $2^{\text {Emxl-Cre }}$ animals were born at normal Mendelian ratio. These mutant animals became runted and succumbed around 1 month after birth. The Terf $2^{\text {Emxl-Cre }}$ brains showed complete loss of the brain region in which Emxl-Cre is expressed (Fig. 1a, b). Terf $2^{\text {LoxP/+ }}$;Nestin-Cre or Emx1-Cre animals did not show any discernable neurological defects, so these genotypes of animals alone with WT animals were considered as control groups. 
$\mathbf{a}$
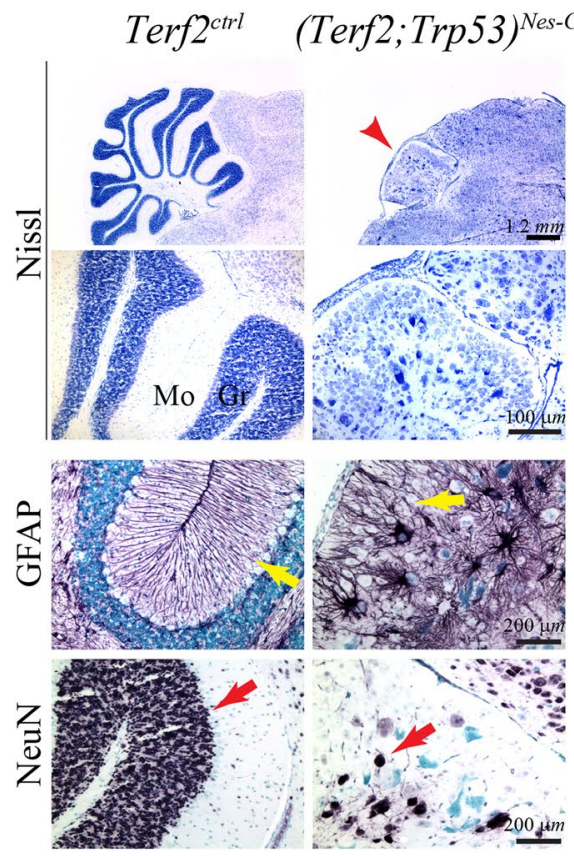
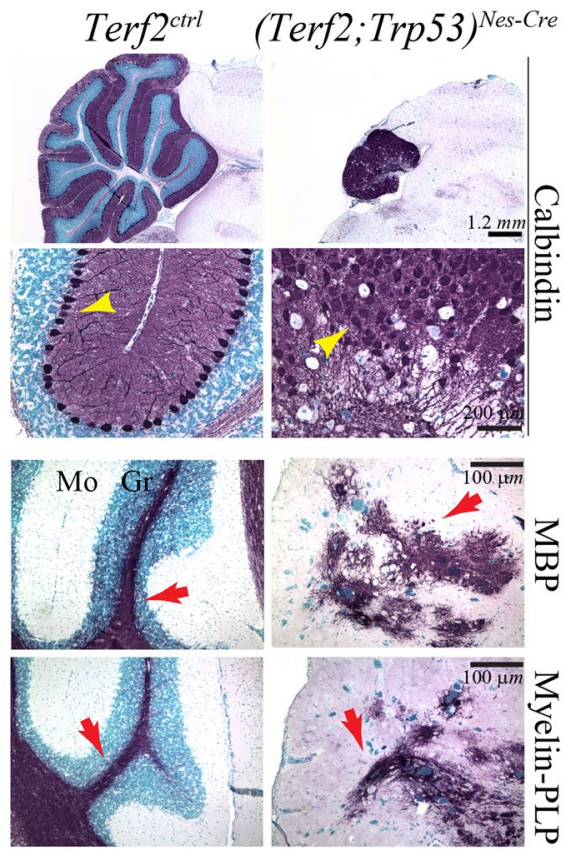

$\operatorname{Terf} 2^{\text {Emxl-Cre }}$

b

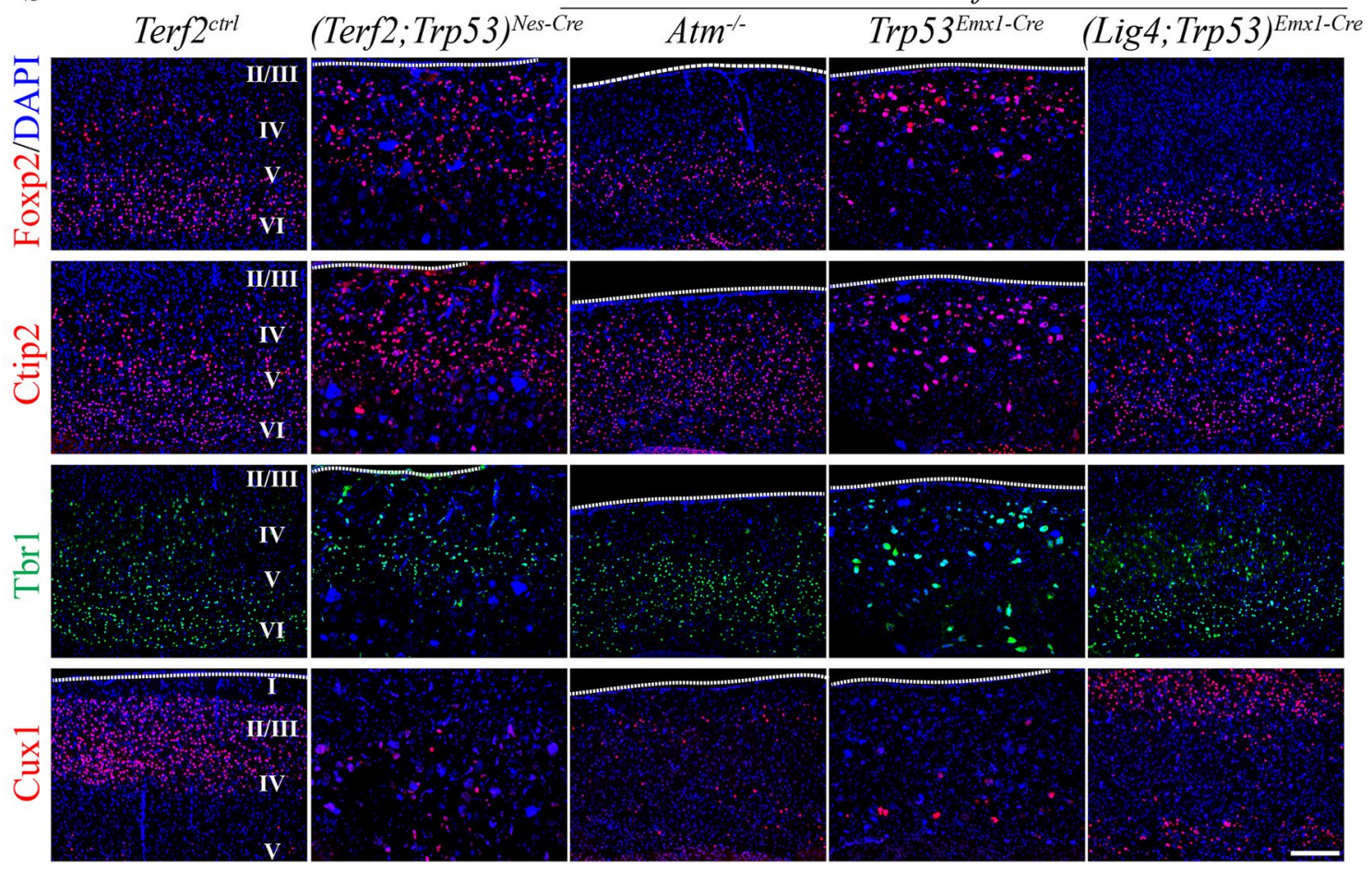

Terf 2 inactivation induced massive neural apoptosis during development

Loss of the brain regions in which Cre recombinase was expressed at birth led us to examine the embryonic brains during neurogenesis. The Terf $2^{\text {Nes-Cre }}$ embryos at E13.5 showed massive apoptosis measured by TUNEL throughout the developing brain (Fig. 2a). As a result, there was no proper brain structure found by E15.5 in a Nestin-Cre background (Fig. 2b). Similarly, Terf2 $2^{\text {Emxl-Cre embryos }}$ had only the vestige of the forebrain with residual apoptosis at E13.5 (Fig. 2c), and a complete disappearance of the Emxl-Cre expressing areas by E15.5 (Fig. 2d), while the ganglionic eminence in which Emxl-Cre is not expressed was intact during neurogenesis. These data suggest an essential requirement of TERF2 and the 
४Fig. 3 Terf2 inactivation disrupted the brain structure. a Developmental defects in the (Terf2;Trp53) ${ }^{\text {Nes-Cre }}$ cerebellum. Nissl staining indicates that the (Terf2;Trp53) Nes-Cre cerebellum was much smaller (red arrowhead) and the size of cells inside was bigger and not organized. The Purkinje cell layer (yellow arrowhead) detected by Calbindin immunostaining displayed the complete misalignment of the layer and could not be found as a single cell layer as shown in the control brain. Glial fibrillary acidic protein (GFAP) immunoreactivity shows the disruption of the Bergmann glial network (yellow arrow). The populations of neurons (NeuN immuno-positive) and oligodendrocytes (MBP and Myelin-PLP immuno-positive) were strikingly reduced, and the structure was disorganized (red arrows). These cerebellar defects lead to severe ataxia in the (Terf2;Trp53) $)^{\text {Nes-Cre }}$ animals (see the accompanied video clip). Mo the molecular layer in the cerebellum, $\mathrm{Gr}$ the granule cell layer in the cerebellum, Ctrl control. Scale bars are as indicated in the figures. b Disruption of the six-layered cortical structure. The layered cortical structure in the 3-week-old brain was examined with four different markers; the upper layers-Cux1; the lower layers-Tbr1, Ctip2, Foxp2. The rescued part of the Terf2-null cortex in either Atm or Trp53 deficiency $\left((\text { Terf } 2 ; \text { Trp53 })^{\text {Nes-Cre }}\right.$, Terf $2^{\text {Emxl-Cre }} ;$ Atm $^{-1-}$ and $\left.(\text { Terf2;Trp53 })^{\text {Emxl-Cre }}\right)$ did not form the upper layers (Cux1 immuno-positive), and the layers IV, V, VI were located to the upper part of the cortex. In contrast, the

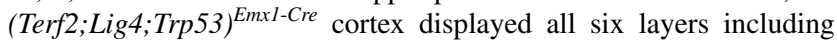
the upper layers (Cux1 immuno-positive). The size of immunopositive cells to the layer markers in the Terf2/Trp53 dual null cortex was much bigger and less organized than that of controls. Roman numeric signs indicate the cortical layers. The white dotted lines indicate the surface of the cerebral cortex. The scale bar is $100 \mu \mathrm{m}$

importance of telomere stability for cell survival during neurogenesis.

\section{Atm and Trp53, but not Atr, inactivation rescued neural apoptosis resulting from $\operatorname{Terf} 2$ deficiency}

Previously, it has been demonstrated that DNA damage triggered by Terf2 inactivation in vitro induced Atm-dependent Atr-independent DDR (Karlseder et al. 1999; Celli and de Lange 2005; Zhang et al. 2006, 2007; Denchi and de Lange 2007). So, next we tested the in vivo involvement of Atm and Atr, as well as Trp53, a common downstream substrate, in lethality and massive neural apoptosis resulting from Terf2 inactivation during neurogenesis. Floxed Terf2 animals were cross-bred with Atr (conditional inactivation: Atr ${ }^{\text {Nes-Cre }}$ and Atr ${ }^{\text {Emxl-Cre }}$ ), Atm (germline inactivation: Atm $^{-/-}$) or Trp53 (conditional inactivation; Trp53 $3^{\text {Nes-Cre }}$ and Trp53 $3^{\text {Emxl-Cre }}$ ) animals. Similar to the in vitro situation (Denchi and de Lange 2007; Karlseder et al. 1999), Atr inactivation did not have any influence on the phenotypes observed in both Terf $2^{\text {Nes-Cre }}$ and Terf $2^{\text {Emxl-Cre }}$ animals (Fig. 2). Terf2 $2^{\text {Emxl-Cre }}$; $\mathrm{Atm}^{-1-}$ and (Terf2;Trp53) Emxl-Cre animals also did not show any discernible improvement in gross phenotypes including smaller body size and shorter life span observed in the $\operatorname{Terf} 2^{\text {Emxl-Cre }}$ animals (data not shown).

In a Nestin-Cre background, Atm inactivation could not rescue prenatal lethality resulting from Terf 2 inactivation, while $\left(\right.$ Terf2;Trp53) ${ }^{\text {Nes-Cre }}$ animals were born alive.
Noticeably, (Terf2;Trp53) Nes-Cre animals displayed severe ataxia, hence could live only up to the time of weaning (supplementary video clip). This severe ataxic phenotype resulted from the malformation of the cerebellum which was very small and did not have any organized structure of the cerebellum, particularly a complete disruption of the Purkinje cell layer (Fig. 3a). Yet the mutant cerebellum contained all of the cellular components including Purkinje cells (Calbindin immuno-positive), Bergmann glia (glial fibrillary acidic protein (GFAP) immuno-positive), and oligodendrocytes (myelin basic protein (MBP) and myelin proteolipid protein (Myelin-PLP) immuno-positive), except granule cells (NeuN immuno-positive) (Fig. 3a). Tumorigenicity in the nervous system of the (Terf2;Trp53) $)^{\text {Nes-Cre }}$ animals could not be evaluated because of a short life span.

Although both Atm and Trp53 inactivation could reduce apoptosis dramatically in the Terf2-null brains (Fig. 2), there was a difference between these two genetic backgrounds. Neural cell death in both Terf2 ${ }^{\text {Nes-Cre }}$ and Ter$f 2^{\text {Emxl-Cre }}$ embryos had disappeared by E15.5 in a Trp53null background, whereas Atm inactivation could not stall most of the apoptosis in the ventricular zone (VZ) where neural progenitor cells are located in (Fig. 2d).

\section{The multiple defects were found in the Terf2-null brains}

Although neuron-specific class III $\beta$-tubulin (Tuj1), which is a marker for postmitotic neurons, showed a normal distribution in the developing brains of the Terf2/Atm and Terf2/ p53 double null embryos (Fig. 2b), the restored portion in the mature brains exhibited several faulty features. Trp53 inactivation led to better restoration of the missing parts in the Terf2-null brain than Atm deficiency did. However, the restoration was still incomplete (Fig. 1b). The hippocampus was not restored in the Terf2/Atm and Terf2/Trp53 double null brains (Fig. 1b).

Next, we analyzed the six-layered cerebral cortical structure created in an inside-out manner during development (Greig et al. 2013). The Foxp2, Ctip2, and Tbr1 immunopositive neurons, which are generated during an early stage of cortical development and localized in the lower layers of the cerebral cortex in normal development, were found in the upper cortical part of the (Terf2;Trp53) $)^{\text {Nes-Cre }}$ and (Terf2;Trp53) ${ }^{\text {Emxl-Cre }}$ brains (Fig. 3b). Similarly, the Ter$\mathrm{f}^{\text {Emxl-Cre }} ; \mathrm{Atm}^{-/-}$cortex showed mis-localization of Ctip2 and Tbr1 immuno-positive neurons. Furthermore, there were no proper upper layers formed (layers I, II, and III), which were Cux1 immuno-positive, in both the Terf2/Atm and Terf2/Trp53 double null cortices, suggesting that the Terf2-null developing brain could not generate cortical neurons at the later stage during development in both Atm- and Trp53-deficient backgrounds (Fig. 3b). 


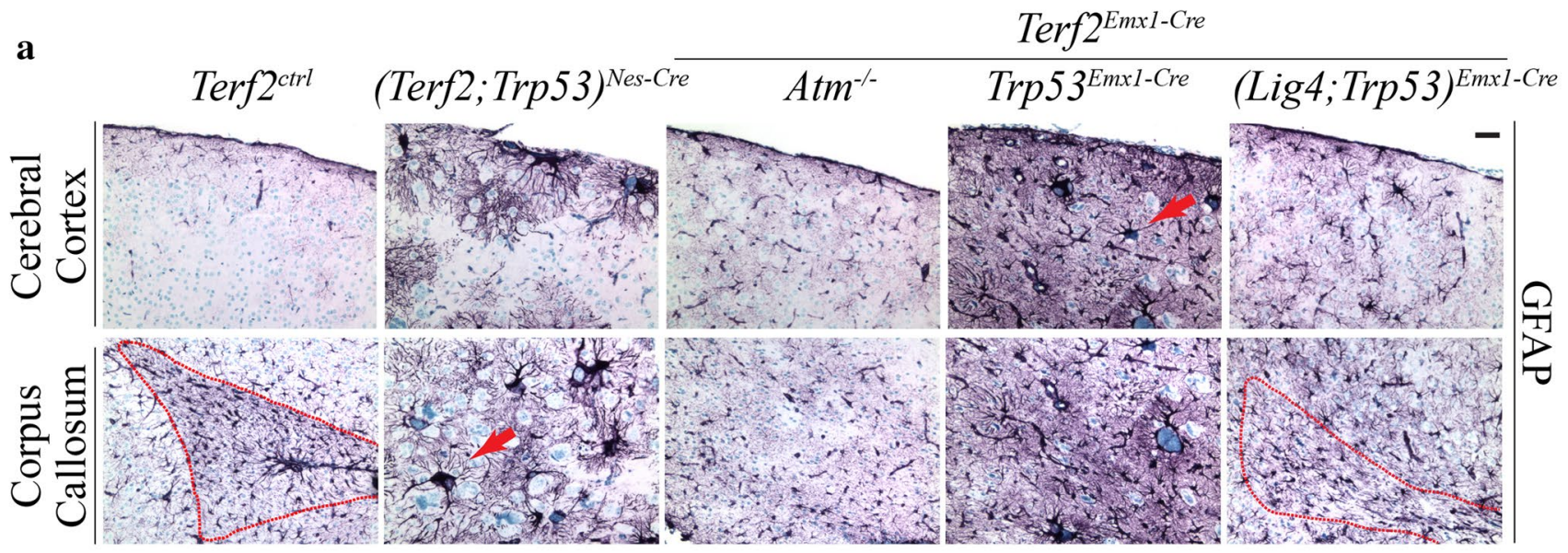

b

$\operatorname{Terf2} 2^{\text {Emxl-Cre }}$
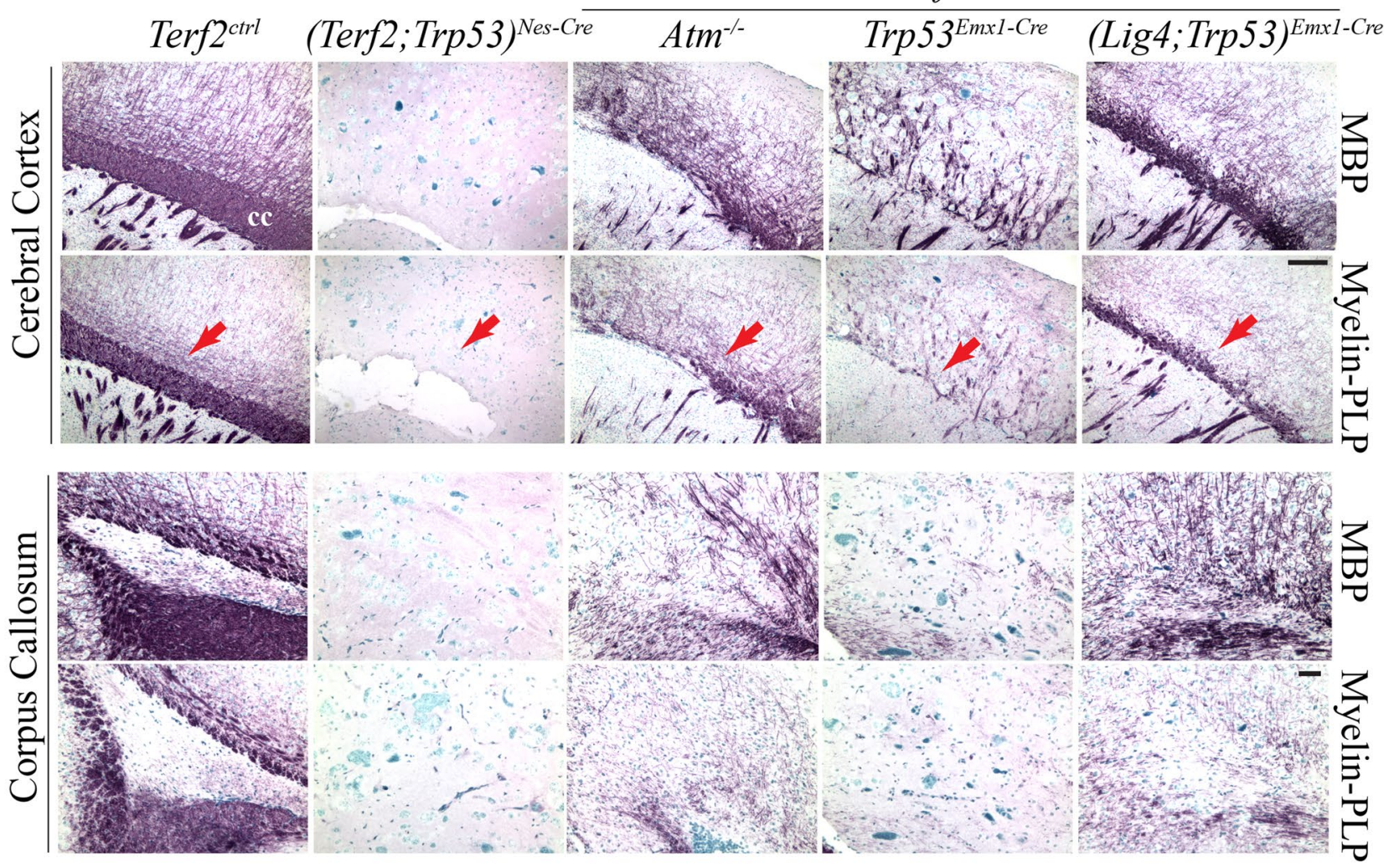

Fig. 4 Defective glia network was formed in the mutant brain. a Increased immunoreactivity of GFAP in the Terf 2 mutant brain. The Terf2-null brains in both Atm- and Trp53-deficient backgrounds showed the high level of GFAP immuno-staining compared to that of the control brain, which is a common feature found in the brain of genomic instability animal models. The corpus callosum, which is a glia-rich structure, was not defined in the Terf2-null brain $\left((\text { Terf2;Trp53 })^{\text {Nes-Cre }}\right.$, Terf $2^{\text {Emxl-Cre }} ;$ Atm $^{-1-}$ and $\left.(\text { Terf2;Trp53 })^{\text {Emxl-Cre }}\right)$. The (Terf2;Lig4;Trp53) Emxl-Cre brain showed partial recovery of the corpus callosum. The red dotted lines demarcate the normal corpus callosum in the control brain and the partially restored corpus callosum in the (Terf2;Lig4;Trp53) ${ }^{\text {Emxl-Cre }}$ brain. The size of GFAP immuno-positive cells in the Terf2/Trp53 double null brains, not in both Terf2/Atm double and Terf2/Lig4/Trp53 triple deficient brains, was bigger than that of controls (red arrows). The scale bar is $200 \mu \mathrm{m}$. b Defective oligodendrocyte network in the Terf 2 mutant brain. Oligodendrocytes were detected by two different markers: MBP (myelin basic protein) and Myelin-PLP (proteolipid protein). The Terf $2^{\text {ctrl }}$ cerebral cortex displayed a rich network of oligodendrocytes, particularly in the corpus callosum. However, the Terf2 conditional knockout brains in all different genetic backgrounds showed a dramatic reduction of immunopositivity to MBP/MyelinPLP, and agenesis of the corpus callosum (red arrows), in contrast to the increased astrocyte population in the Terf2-null brains (A panel above). And the genetic combination with Atm or Trp53 deficiency could not improve this defect. However, Lig4 inactivation resulted in partial recovery of the corpus callosum in the $(\operatorname{Terf} 2 ; \operatorname{Trp} 53)^{\text {Emxl-Cre }}$ brain. The corpus callosum shown in the lower panel was the posterior part of the corpus callosum. The scale bars are $100 \mu \mathrm{m}$ 
Increased GFAP immunoreactivity was one of common features found in the brains of genomic instability animal models (Shull et al. 2009; Lee et al. 2012a, b). So we tested whether Terf2-deficient brains also exhibit increased GFAP immunoreactivity as a sign of genomic instability. Indeed the Terf2-null cortex showed increased GFAP immunopositivity in both Atm- and p53-null backgrounds (Fig. 4a). Interestingly, the size of GFAP immuno-positive cells in Terf2/Trp53 double null brains was relatively big (Fig. 4a). On the contrary, the dramatic reduction of oligodendrocyte population which was visualized by MBP and Myelin-PLP immunoreactivity was found in the Terf2/Atm and Terf2/ Trp53 double null cortices (Fig. 4b). However, all of the Terf2-null cortices were in the absence of the corpus callosum (CC) structure, which functions as a communication path between two cerebral hemispheres (Fig. 4a, b).

\section{Trp53 inactivation resulted in multinucleated giant neural cells in the Terf2-null brain}

Furthermore, we noticed the existence of giant neural cells only in the Terf2/Trp53 double null brains, not in the Terf2/ Atm double null brains (Figs. 3, 4a, 5a). Each giant cell contained irregular shaped multiple nuclei connected to each other by thin strings (Fig. 5a).

Also, the considerable amounts of DNA damage visualized by phosphorylated $\mathrm{H} 2 \mathrm{AX}(\gamma-\mathrm{H} 2 \mathrm{AX})$ foci formation, which is a good marker for DNA strand breaks, were detected in all of the Terf2-null brains, but not in the control brain (Fig. 5a). In addition, telomere in situ visualization using a telomere-PNA probe showed its conjugated CY3 signals in the Terf2-null brains (Fig. 5a). These telomerePNA signals were not noticeable in the control brain, suggesting that telomeres in Terf2-null neural cells were readily accessible by the telomere-PNA probe since they were not well protected.

Next we examined whether multinucleated giant neural cells were formed during neurogenesis. Certainly, $\gamma-\mathrm{H} 2 \mathrm{AX}$ foci formation in the Terf2-null brains, particularly in the VZ of the developing brains, was dramatically increased in both Atm- and Trp53-deficient backgrounds (Fig. 5b). However, the chromosome mass at metaphase visualized by phosphorylated $\mathrm{H} 3$ immunoreactivity $(\mathrm{H} 3 \mathrm{pS} 10)$ showed a significant increase only in the Terf2/Trp53 double null neural progenitors (Fig. 5b). This giant chromosomal mass was not observed in an Atm-null background. It is possible that this giant chromosomal aggregation might partially result from incomplete cell division, since multiple centrosomes detected by $\gamma$-tubulin immunoreactivity in a single cell were observed only in the Terf2/Trp53 double null neural cells at metaphase (Fig. 5b). Even though DNA damage detected by $\gamma$-H2AX foci was evident, neural progenitor cells with giant chromosomal mass were not observed in the Pot $1 a^{\text {Nes-Cre }}$ embryonic brains (Fig. 5b); consequently, there were no multinucleated giant neural cells found in the Pot $1 a^{\text {Nes-Cre }}$ mature brains (Lee et al. 2014).

\section{DNA ligase IV plays a role in neural abnormalities due to Terf 2 deficiency during neurogenesis}

Previously it was reported that Lig4 plays a role in abnormal fusions of telomere ends in Terf2-deficient cells (Celli and de Lange 2005; Smogorzewska et al. 2002). So we tested whether Lig4 inactivation during neurogenesis could alleviate neural abnormalities observed in the (Terf2/Trp53) Emxl-Cre brain. As described before (Lee et al. 2012a), the (Lig4;Trp53) ${ }^{\text {Emxl-Cre }}$ brain did not show any neural phenotypes related to telomere dysfunction. The triple conditional knockout animals (hereafter (Terf2;Lig4;Trp53) ${ }^{\text {Emxl-Cre }}$ ) were born alive, but the (Terf2;Lig4;Trp53) ${ }^{\text {Emxl-Cre }}$ animals died around 1 month of age similar to the (Terf2;Trp53) ${ }^{\text {Emxl-Cre }}$ animals.

Neuropathological analysis revealed that the neurological abnormalities were moderately corrected in the $(\text { Terf } 2 \text {;Lig4;Trp53) })^{\text {Emxl-Cre }}$ brain. During embryogenesis, the reduction of neural cell death in the (Terf2;Lig4;Trp53) Emxl-Cre embryos was the same as the (Terf2;Trp53)Emxl-Cre embryos, most likely due to the effect of Trp53 inactivation (Fig. 2d). However, proliferating cells at metaphase in the (Terf2;Lig4;Trp53) EmxI-Cre VZ were similar to those with two centrosomes found in control embryos (Fig. 5b). Consequently, the most obvious correction was disappearance of multinucleated giant cells in the triple conditional null mature brain (Figs. 4a, 5a). In addition, the upper layers of the cerebral cortex, which are Cux1 immuno-positive, were formed in the triple null brain (Fig. 3b). However, this recovery by Lig4 inactivation was not complete, such as partial reconstruction of the hippocampus and CC compared to the control groups (Figs. 1b, 4).

\section{Discussion}

Telomere homeostasis is essential for brain development in the mouse

The role of TERF2 and POT1 as components of the Shelterin complex is to protect the telomere ends so that genomic integrity is maintained (Celli and de Lange 2005; Denchi and de Lange 2007; Karlseder et al. 1999). Previously the Terf 2 gene of the mouse was conditionally targeted only in the liver and skin (Bojovic et al. 2013; Lazzerini Denchi et al. 2006; Martinez et al. 2014). Terf2 inactivation in the basal layer of epidermis using a K14Cre animal line did not cause embryonic lethality (Bojovic et al. 2013), while Terf2 inactivation in epidermal stem cells 

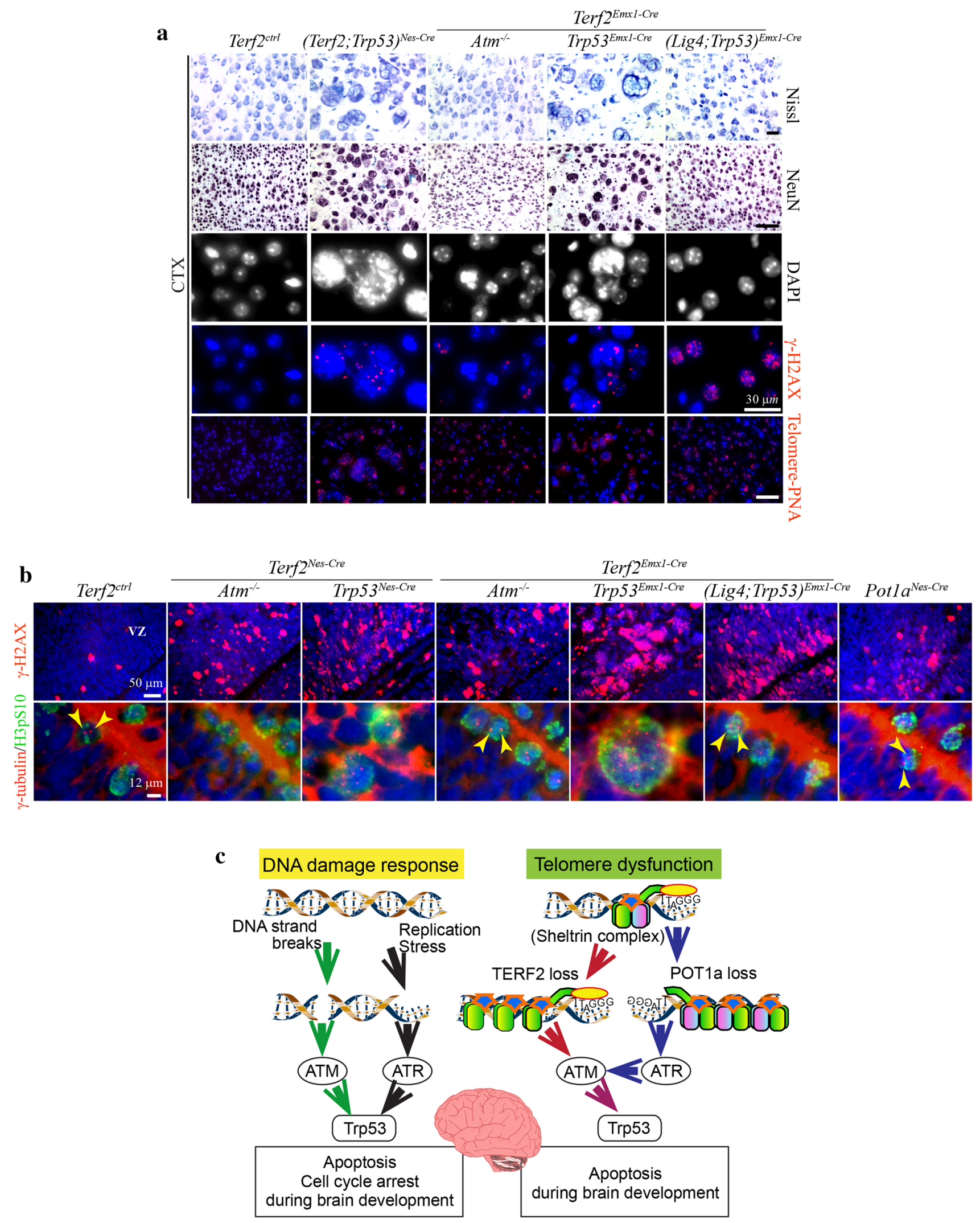
4Fig. 5 The multinucleated giant neural cells were found only in the Terf2/Trp53 double null brain. a Giant neural cells in the Terf2/ Trp53 double null brains and a sign of DNA damage in the Terf2 null brain. The neural cells including neurons in the brain, particularly the cerebral cortex (CTX), were examined by Nissl staining and NeuN immunoreactivity. Giant neural cells were found only in the $\left(\operatorname{Terf2}\right.$;Trp53) ${ }^{\text {Nes-Cre }}$ and (Terf2;Trp53) Emxl-Cre cortices. Giant neural cells had multiple nuclei in a single cell visualized by DAPI staining in the Terf2/Trp53 double deficient cortex. This kind of giant neural cells were not observed in the Terf $2^{\text {Emxl-Cre }} ; \mathrm{Atm}^{-1-}$ and (Terf2;Lig4;Trp53) Emxl-Cre cortices. DNA damage or breaks could be visualized by immunostaining of phosphorylated $\mathrm{H} 2 \mathrm{AX}(\gamma-\mathrm{H} 2 \mathrm{AX})$ as foci formation in the nucleus. $\gamma-\mathrm{H} 2 \mathrm{AX}$ foci were abundant in the giant nuclei of the Terf2/Trp53 double null cortices. Since Lig4 deficiency itself results in accumulation of $\gamma$-H2AX foci, the

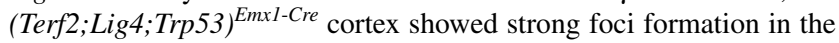
nucleus. Telomeres were visualized by hybridization with TelomerePNA probe conjugated with CY3 (red). Only the Terf2-null cortices in all different genetic backgrounds showed the high level of PNA probe positivity indicating that the PNA-telomere probe was hybridized better with telomeres in the Terf2-null brains. The blue staining was DAPI staining for $\gamma$-H2AX immunostaining and PNA-telomere in situ detection. The scale bars are $100 \mu \mathrm{m}$ except $\gamma$-H2AX immunostaining. b The high level of $\gamma-\mathrm{H} 2 \mathrm{AX}$ foci and big chromosomes in the Terf2-null embryonic cortex during embryogenesis. DNA damage visualized by $\gamma$-H2AX foci was evident in the Terf2-null embryonic fore brains in different genetic backgrounds as well as in the Pot1a ${ }^{\text {Nes-Cre }}$ embryonic brain, particularly in the ventricular zone (VZ) of the cortex. A big conglomeration of chromosomes detected by phosphorylated $\mathrm{H} 3$ ( $\mathrm{H} 3 \mathrm{pS} 10)$ immunoreactivity (green staining) was observed only in the Terf2/Trp53 double null metaphase cells $\left((\text { Terf2;Trp53 })^{\text {Nes-Cre }}\right.$ and (Terf2;Trp53) $\left.{ }^{\text {Emxl-Cre }}\right)$, not in Terf2/Atm double and Terf2/Lig4/Trp53 triple null metaphase cells. Centrosomes were visualized by $\gamma$-tubulin immunoreactivity (yellow arrowheads). Only Terf2/Trp53 double null metaphase cells in both Nestin and Emx-1 Cre backgrounds had multiple centrosomes (red staining) in a single-metaphase cell. Terf $2^{\mathrm{Nes}-\mathrm{Cre}} ; \mathrm{Atm}^{-1-}, \operatorname{Terf} 2^{\text {EmxI-Cre }} ; \mathrm{Atm}^{-/-}$

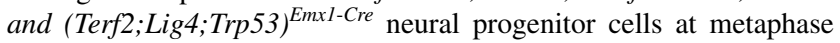
had two centrosomes the same as the control embryonic brain (yellow arrowheads). Potla deficiency (Pot $1 a^{\text {Nes-Cre }}$ ) did not show any similar defects such as a big aggregation of chromosomes and multiple centrosomes. The scale bars are as indicated in the figure. c A schematic illustration of signaling pathways induced by either DNA damage or telomere dysfunction to trigger apoptosis or cell cycle arrest during brain development. Telomere dysfunction resulting from either TERF2 or POT1a inactivation induces neural apoptosis which is ATM-Trp53 dependent during neurogenesis. Terf2 inactivation directly activates ATM-dependent signaling, while Potla inactivation induces ATM activation via ATR signaling during neurogenesis

using a $\mathrm{K} 5$-Cre animal line led to partial embryonic lethality and impaired skin development (Martinez et al. 2014). Similarly, here we demonstrated that a selective inactivation of the Terf 2 gene in the neural progenitor cells resulted in embryonic fatality and loss of brain structures, providing another example that the protective role of TERF2 is important to maintain cellular and organismal viability. This result is clearly different from the animal model for selective inactivation of the Terf 2 gene in the liver that showed normal liver function and regeneration through endoreduplication without cell division (Lazzerini Denchi et al. 2006). The status of cells, such as proliferating vs. resting cells, most likely contributes to this difference in cellular viability as suggested before (Martinez et al. 2014).

Interestingly, there was no similarity of the neural phenotypes between the Terf $2^{\text {Nes-Cre }}$ and Pot $1 a^{\text {Nes-Cre }}$ animals (Lee et al. 2014), even though germline deletion of the Terf 2 or Potla gene in the mouse resulted in embryonic lethality (Celli and de Lange 2005; Hockemeyer et al. 2006; Wu et al. 2006), Potla inactivation in neural progenitor cells did not induce massive neural apoptosis during embryogenesis, and the neurological defects resulting from Potla inactivation were restricted mainly to the cerebellum (Lee et al. 2014). Furthermore, Pot $1 a^{\text {Nes-Cre }} ; \operatorname{Trp} 53^{-1-}$ animals did not show any sign of ataxia. On the contrary, Terf 2 inactivation in the neural progenitor cells induced more global effects throughout the central nervous system. Also it appeared that there was a differentiation defect of lateborn neurons originated from Terf2-null neural progenitor cells which underwent more cell divisions in a Trp53-deficient background.

As illustrated in Fig. 5c, it is possible that the Shelterin complex with all components including POT1 presents only at the end of telomeres where the $3^{\prime}$ single-stranded GC rich overhang is exposed (de Lange 2005; Gramatges and Bertuch 2013; Palm and de Lange 2008). For this reason, the impact resulting from Terf 2 inactivation in the neural progenitor cells was more severe than that of Potla inactivation in the murine nervous system.

\section{ATM and Trp53 are key signaling mediators in telomere dysfunction due to Terf2 inactivation during brain development in the mouse}

One of the interesting observations was the entity of multinucleated giant neural cells only in the Terf2/Trp53 conditional knockout mature brain, possibly resulting from endoreduplication without proper cell division as suggested in other Terf2 conditional knockout animal models (Lazzerini Denchi et al. 2006; Martinez et al. 2014; Ullah et al. 2009). It had been demonstrated that endoreduplication and mitotic failure in a Trp53-dependent manner during telomere crisis lead to polyploid cell accumulation (Davoli and de Lange 2012; Pampalona et al. 2012; Davoli et al. 2010). This defect of multinucleated giant cells was resolved by Lig4 inactivation, suggesting that the ligation function of LIG4 plays a role in this particular neural defect due to telomere dysfunction resulting from Terf2 inactivation during brain development.

Trp53 inactivation suppressed neural apoptosis triggered by Terf 2 inactivation in the entire developing nervous system including the VZ in which big metaphase cells could be formed, whereas Atm deficiency could not inhibit programmed cell death in the VZ of the Terf2-null embryonic brain. Therefore, multinucleated giant neural cells 
were not observed in the Terf2/Atm knockout brain. Also this result suggests that $\operatorname{Trp53}$ activation to induce neural apoptosis in the Terf2-null VZ was Atm-independent. This observation was consistent with the previous reports demonstrating that ATM is involved in neural apoptosis via Trp53 activation in the postmitotic zone, not in the VZ (Lee et al. 2000, 2001; Orii et al. 2006). Apparently, ATR is not the key kinase to activate Trp53 signaling in the Terf2-null VZ, since Atr inactivation did not have any effect on the neural defects in the Terf2-null brain, similar to the in vitro situation (Denchi and de Lange 2007). In addition, there was likely no cross-talk between Atm and Atr signalings responding to telomere dysfunction resulting from Terf 2 inactivation during brain development, in contrast to the situation of Potla deficiency in the developing brain (Lee et al. 2014). Alternatively, DNA-dependent protein kinase (DNA-PK) might be involved in the Trp53 signaling in the VZ upon DDR induced by Terf2 deficiency (Rybanska-Spaeder et al. 2014).

Taken all together in combination with our previous report (Lee et al. 2014), we demonstrated that TERF2 is more critical to maintain telomere homeostasis than POT1a in the developing mouse brain. Telomere dysfunction by Terf 2 inactivation induces the ATM-Trp53 signaling axis to trigger neural apoptosis as a part of the mechanisms to maintain genomic integrity during neurogenesis as illustrated in Fig. 5c. ATM is also activated via ATR signaling by telomere dysfunction due to Potla inactivation in the same physiological context.

\begin{abstract}
Acknowledgements We are deeply grateful to Dr. Peter McKinnon at St. Jude Children's Research Hospital, USA for providing experimental materials and vital discussion. We thank the Hartwell Center for biotech support, the cytogenetics core for chromosome analysis and the Animal Resource Center for animal husbandry. We also thank Jingfeng Zhao, Yang Li and Dr. Helen Russell for technical support as well as Stuart Horwitz for English editing. YSL was supported by the NRF of Korea grant funded by the MSIP (Nos. 2011-0030043 and NRF-2014R1A1A2056224). YSL is also supported by the new faculty research fund of Ajou University School of Medicine.
\end{abstract}

\section{Compliance with ethical standards}

Conflict of interest We declare no conflict of interest regarding this paper.

Ethical approval All procedures using animal models were approved by the IACUC.

Open Access This article is distributed under the terms of the Creative Commons Attribution 4.0 International License (http://creativecommons.org/licenses/by/4.0/), which permits unrestricted use, distribution, and reproduction in any medium, provided you give appropriate credit to the original author(s) and the source, provide a link to the Creative Commons license, and indicate if changes were made.

\section{References}

Bojovic B, Ho HY, Wu J, Crowe DL (2013) Stem cell expansion during carcinogenesis in stem cell-depleted conditional telomeric repeat factor 2 null mutant mice. Oncogene 32(43):51565166. doi:10.1038/onc.2012.555

Celli GB, de Lange T (2005) DNA processing is not required for ATM-mediated telomere damage response after TRF2 deletion. Nat Cell Biol 7(7):712-718. doi:10.1038/ncb1275

Davoli T, de Lange T (2012) Telomere-driven tetraploidization occurs in human cells undergoing crisis and promotes transformation of mouse cells. Cancer Cell 21(6):765-776. doi:10.1016/j.ccr.2012.03.044

Davoli T, Denchi EL, de Lange T (2010) Persistent telomere damage induces bypass of mitosis and tetraploidy. Cell 141(1):8193. doi:10.1016/j.cell.2010.01.031

de Lange T (2005) Shelterin: the protein complex that shapes and safeguards human telomeres. Genes Dev 19(18):2100-2110. doi:10.1101/gad.1346005

Denchi EL, de Lange T (2007) Protection of telomeres through independent control of ATM and ATR by TRF2 and POT1. Nature 448(7157):1068-1071. doi:10.1038/nature06065

Gorski JA, Talley T, Qiu M, Puelles L, Rubenstein JL, Jones KR (2002) Cortical excitatory neurons and glia, but not GABAergic neurons, are produced in the Emx1-expressing lineage. $\mathbf{J}$ Neurosci 22(15):6309-6314

Gramatges MM, Bertuch AA (2013) Short telomeres: from dyskeratosis congenita to sporadic aplastic anemia and malignancy. Transl Res 162(6):353-363. doi:10.1016/j.trsl.2013.05.003

Graus-Porta D, Blaess S, Senften M, Littlewood-Evans A, Damsky C, Huang Z, Orban P, Klein R, Schittny JC, Muller U (2001) Beta1-class integrins regulate the development of laminae and folia in the cerebral and cerebellar cortex. Neuron 31(3):367-379

Greig LC, Woodworth MB, Galazo MJ, Padmanabhan H, Macklis JD (2013) Molecular logic of neocortical projection neuron specification, development and diversity. Nat Rev Neurosci 14(11):755-769. doi:10.1038/nrn3586

Hockemeyer D, Daniels JP, Takai H, de Lange T (2006) Recent expansion of the telomeric complex in rodents: two distinct POT1 proteins protect mouse telomeres. Cell 126(1):63-77. doi:10.1016/j.cell.2006.04.044

Karlseder J, Broccoli D, Dai Y, Hardy S, de Lange T (1999) p53- and ATM-dependent apoptosis induced by telomeres lacking TRF2. Science 283(5406):1321-1325

Lazzerini Denchi E, Celli G, de Lange T (2006) Hepatocytes with extensive telomere deprotection and fusion remain viable and regenerate liver mass through endoreduplication. Genes Dev 20(19):2648-2653. doi:10.1101/gad.1453606

Lee Y, Barnes DE, Lindahl T, McKinnon PJ (2000) Defective neurogenesis resulting from DNA ligase IV deficiency requires Atm. Genes Dev 14(20):2576-2580

Lee Y, Chong MJ, McKinnon PJ (2001) Ataxia telangiectasia mutated-dependent apoptosis after genotoxic stress in the developing nervous system is determined by cellular differentiation status. J Neurosci 21(17):6687-6693

Lee Y, Katyal S, Downing SM, Zhao J, Russell HR, McKinnon PJ (2012a) Neurogenesis requires TopBP1 to prevent catastrophic replicative DNA damage in early progenitors. Nat Neurosci 15(6):819-826. doi:10.1038/nn.3097

Lee Y, Shull ER, Frappart PO, Katyal S, Enriquez-Rios V, Zhao J, Russell HR, Brown EJ, McKinnon PJ (2012b) ATR maintains select progenitors during nervous system development. EMBO J 31(5):1177-1189. doi:10.1038/emboj.2011.493 
Lee Y, Brown EJ, Chang S, McKinnon PJ (2014) Pot1a prevents telomere dysfunction and ATM-dependent neuronal loss. J Neurosci 34(23):7836-7844. doi:10.1523/JNEUROSCI.4245-13.2014

Lee Y, Choi I, Kim J, Kim K (2016) DNA damage to human genetic disorders with neurodevelopmental defects. J Genet Med 13(1):1-13. doi:10.5734/jgm.2016.13.1.1

Lovejoy CA, Cortez D (2009) Common mechanisms of PIKK regulation. DNA Repair 8(9):1004-1008. doi:10.1016/j. dnarep.2009.04.006

Martinez P, Ferrara-Romeo I, Flores JM, Blasco MA (2014) Essential role for the TRF2 telomere protein in adult skin homeostasis. Aging Cell 13(4):656-668. doi:10.1111/acel.12221

McKinnon PJ (2012) ATM and the molecular pathogenesis of ataxia telangiectasia. Ann Rev Pathol 7:303-321. doi:10.1146/ annurev-pathol-011811-132509

McKinnon PJ (2013) Maintaining genome stability in the nervous system. Nat Neurosci 16(11):1523-1529. doi:10.1038/nn.3537

Nam EA, Cortez D (2011) ATR signalling: more than meeting at the fork. Biochem J 436(3):527-536. doi:10.1042/BJ20102162

Orii KE, Lee Y, Kondo N, McKinnon PJ (2006) Selective utilization of nonhomologous end-joining and homologous recombination DNA repair pathways during nervous system development. Proc Natl Acad Sci USA 103(26):10017-10022. doi:10.1073/ pnas.0602436103

Palm W, de Lange T (2008) How shelterin protects mammalian telomeres. Annu Rev Genet 42:301-334. doi:10.1146/annurev. genet.41.110306.130350

Pampalona J, Frias C, Genesca A, Tusell L (2012) Progressive telomere dysfunction causes cytokinesis failure and leads to the accumulation of polyploid cells. PLoS Genet 8(4):e1002679. doi:10.1371/journal.pgen.1002679

Rybanska-Spaeder I, Ghosh R, Franco S (2014) 53BP1 mediates the fusion of mammalian telomeres rendered dysfunctional by DNA-PKcs loss or inhibition. PLoS One 9(9):e108731. doi:10.1371/journal.pone.0108731

Sfeir A, de Lange T (2012) Removal of shelterin reveals the telomere end-protection problem. Science 336(6081):593-597. doi:10.1126/science. 1218498

Shull ER, Lee Y, Nakane H, Stracker TH, Zhao J, Russell HR, Petrini JH, McKinnon PJ (2009) Differential DNA damage signaling accounts for distinct neural apoptotic responses in ATLD and NBS. Genes Dev 23(2):171-180. doi:10.1101/gad.1746609

Smogorzewska A, Karlseder J, Holtgreve-Grez H, Jauch A, de Lange $\mathrm{T}$ (2002) DNA ligase IV-dependent NHEJ of deprotected mammalian telomeres in G1 and G2. Curr Biol CB 12(19):1635-1644

Tronche F, Kellendonk C, Kretz O, Gass P, Anlag K, Orban PC, Bock R, Klein R, Schutz G (1999) Disruption of the glucocorticoid receptor gene in the nervous system results in reduced anxiety. Nat Genet 23(1):99-103. doi:10.1038/12703

Ullah Z, Lee CY, Lilly MA, DePamphilis ML (2009) Developmentally programmed endoreduplication in animals. Cell Cycle 8(10):1501-1509. doi:10.4161/cc.8.10.8325

Wu L, Multani AS, He H, Cosme-Blanco W, Deng Y, Deng JM, Bachilo O, Pathak S, Tahara H, Bailey SM, Deng Y, Behringer RR, Chang S (2006) Pot1 deficiency initiates DNA damage checkpoint activation and aberrant homologous recombination at telomeres. Cell 126(1):49-62. doi:10.1016/j.cell.2006.05.037

Zhang P, Furukawa K, Opresko PL, Xu X, Bohr VA, Mattson MP (2006) TRF2 dysfunction elicits DNA damage responses associated with senescence in proliferating neural cells and differentiation of neurons. $\mathrm{J}$ Neurochem 97(2):567-581. doi:10.1111/j.1471-4159.2006.03779.x

Zhang P, Dilley C, Mattson MP (2007) DNA damage responses in neural cells: focus on the telomere. Neuroscience 145(4):1439-1448. doi:10.1016/j.neuroscience.2006.11.052 